\title{
O diálogo crítico nas relações educativas imbricado aos movimentos de ação-reflexão
}

\author{
Critical dialogue in educational relations imbricated to action- \\ reflection movements
}

\section{El diálogo crítico en las relaciones educativas imbricado a los movimientos de acción-reflexión}

\begin{abstract}
André Luis Castro de Freitas'
Universidade Federal do Rio Grande (FURG), Professor associado no Programa de PósGraduação em Engenharia da Computação e no Programa de Pós-Graduação em Educação Ambiental

\section{Luciane Albernaz de Araujo Freitas ${ }^{2}$}

Instituto Federal Sul-Rio-Grandense (IFSUL), Professora no Programa de Pós-Graduação em Educação e Tecnologia
\end{abstract}

Resumo: A partir de um estudo descritivo crítico, fundamentado em uma pesquisa qualitativa, bibliográfica, adensada pelo pensamento educacional de Paulo Freire, teve-se como intenção refletir sobre os pressupostos que demonstravam premente o exercício do diálogo crítico nas relações educativas, bem como estudar a sua relação com os movimentos de ação-reflexão diante dos desafios que enfrenta a escola contemporânea. Na primeira parte do texto, resgatam-se nas obras freirianas, as quais abordam o assunto, a importância do exercício do diálogo, cuja raiz está na educação popular, como relação em que os seres humanos pronunciam e modificam o mundo. A partir dessa compreensão, esse mesmo mundo pronunciado volta-se problematizado aos sujeitos, gerando novas ações no contexto histórico. Na segunda parte, aproxima-se a discussão dos desafios vividos pelos seres humanos no momento contemporâneo, em que tanto educadores quanto educandos estão tomados por fragmentos impostos pelos modelos de produção e consumo vigentes. Nessas condições, fez-se objetivo neste estudo elaborar aproximações e distanciamentos entre a educação popular e a educação formal, fundamentados

Doutor e Mestre em Ciência da Computação pela Universidade Federal do Rio Grande do Sul; Doutor e Mestre em Educação pela Universidade Federal de Pelotas.

2 Doutora em Educação Ambiental pela Universidade Federal do Rio Grande; Mestre em Desenvolvimento Social pela Universidade Católica de Pelotas. 
na razão de que o educando aprende quando, pelo conhecimento científico trabalhado, ressignifica seus saberes do cotidiano e consegue gerar ações que venham a provocar transformações no meio em que está inserido.

Palavras-chave: Educação popular. Educação formal. Diálogo. Ação-reflexão.

Abstract: Based on a qualitative, bibliographical research, based on the educational thinking of Paulo Freire, the article aims to reflect on the presuppositions that demonstrate the exercise of critical dialogue in educational relations, as well as, to study its relation with the movements of action-reflection before the challenges faced by the contemporary school. In the first part of the text, it is taken up in the Freirian works, which address the subject, the importance of the exercise of dialogue, the root of which is in popular education, as a relation in which human beings pronounce and modify the world. From this understanding, this same pronounced world becomes problematize to the subjects, generating new actions in the historical context. In the second part, the discussion approaches the challenges lived by human beings in the contemporary moment in which both educators and students are taken by fragments imposed by the current models of production and consumption. Under these conditions, the purpose of the study is to elaborate approximations and distances between popular education and formal education, based on the reason that the learner learns when, through scientific knowledge, he reorganizes his everyday knowledge and is able to generate actions that may provoke transformations in the environment in which it is inserted.

Keywords: Popular education. Formal education. Dialogue. Action-reflection.

Resumen: A partir de un estudio descriptivo crítico, fundamentado en una investigación cualitativa, bibliográfica, adensada por el pensamiento educativo de Paulo Freire, se tiene como intención reflexionar sobre los presupuestos que demuestren urgentemente el ejercicio del diálogo crítico en las relaciones educativas, así como, su relación con los movimientos de acción-reflexión ante los desafíos que enfrenta la escuela contemporánea. En la primera parte del texto, se retoma en las obras freirianas, las cuales abordan el asunto, la importancia del ejercicio del diálogo, cuya raíz está en la educación popular, como relación en que los seres humanos pronuncian y modifican el mundo. A partir de esa comprensión, ese mismo mundo pronunciado se vuelve problemático a los sujetos, generando nuevas acciones en el contexto histórico. 
En la segunda parte, se acerca la discusión a los desafíos vividos por los seres humanos en el tiempo contemporáneo en que tanto educadores y educandos están tomados por fragmentos impuestos por los modelos de producción y consumo vigentes. En estas condiciones, se hace objetivo del estudio elaborar acercamientos y distanciamientos entre la educación popular y la educación formal, fundamentado en la razón de que el educando aprende cuando, por el conocimiento científico trabajado, re-significa sus saberes de lo cotidiano y logra generar acciones que vengan a provocar transformaciones en el medio en que está insertado.

Palabras clave: Educación popular. Educación formal. Diálogo. Acciónreflexión.

\section{CONSIDERAÇÕES INICIAIS}

Tendo como foco a problemática da educação e da alfabetização de adultos, Freire demonstra em sua obra a preocupação de superar as injustiças sociais, tendo como fim a transformação da sociedade. Reconhece que essa educação não é suficiente em si mesma, mas relevante ao exercício da transformação, no momento em que afirma, na obra Pedagogia da Indignação, "[...] se a educação sozinha não transforma a sociedade, sem ela tampouco a sociedade muda." (FREIRE, 2014, p. 77). A argumentação do autor está embasada na discussão de que a mudança, para acontecer, demanda que os sujeitos inseridos nos processos educativos se assumam como protagonistas da própria libertação, tarefa essa, não raro, dificultada pelas situações da cotidianidade.

Esse protagonismo é objeto de estudo na obra freiriana no momento em que os seres humanos inseridos em um processo educativo dialético, pelos movimentos de ação-reflexão, exercitam a autotransformação. Dessa maneira, assume-se o pressuposto de que a educação ${ }^{3}$ compreende a autotransformação

\footnotetext{
3 Na obra Educação como prática da liberdade, Freire (1969, p. 111 ) se refere ao processo de alfabetização ao sustentar que esta "[...] não pode ser feita de cima para baixo, como uma doação ou imposição, mas de dentro para fora, pelo próprio analfabeto, apenas com a colaboração do educador."
} 
dos sujeitos, promovendo a postura interferente destes no contexto. Nessas condições, a educação deve estar a favor de que o sujeito tome distância da realidade em que se encontra, para constituir o movimento de inserção crítica, o que resulta na ação sobre a realidade constituída. $\bigcirc$ movimento de açãoreflexão busca desvelar as relações dos seres humanos com o mundo, como modo de ação política, pela consciência de si.

Neste texto, teve-se, inicialmente, como intencionalidade problematizar os diálogos de Paulo Freire com os camponeses chilenos e trabalhadores da Zona da Mata descritos na obra Pedagogia da esperança: um reencontro com a pedagogia do oprimido, para além de considerá-los como motivadores da aprendizagem, mas diálogos nos quais os sujeitos sejam autores de processos de tomada de consciência articulados à educação, inseridos em um movimento de ação-reflexão sobre a realidade constituída. $\bigcirc$ objetivo é desvelar como, nessas relações, os sujeitos se apropriam dos saberes em relação ao contexto vivido tecendo aproximações e distanciamentos à educação formal contemporânea.

Com o intuito de abordar a referida discussão, por meio de um estudo descritivo crítico, fundamentado em uma pesquisa qualitativa, de base bibliográfica, apresenta-se o trabalho nas seguintes temáticas: $\bigcirc$ diálogo com os camponeses e trabalhadores - compreende-se um estudo sobre a aprendizagem fundamentada em um diálogo crítico tal que o diálogo se constitui um articulador do entendimento entre os sujeitos, proporcionando um exercício entre iguais e diferentes, no qual é permitido ouvir o outro, com alteridade; $A$ práxis social e os movimentos de ação-reflexão - destaca-se a necessidade do engajamento dos seres humanos ao contexto vivido, ao que conduz, segundo Freire, ao encaminhamento radical à transformação sociocultural; e Os desafios que enfrenta o momento contemporâneo - compreende-se que o fazer e o refazer o mundo, como tarefa de transformação social, promovem uma renovação cultural, que deve estar presente tanto na educação popular quanto na educação formal. Após, seguem as considerações finais em que se apontam as contribuições do estudo. 


\section{O DIÁLOGO COM OS CAMPONESES E TRABALHADORES}

O diálogo freiriano com os camponeses inicia a partir de uma reflexão na qual, por meio da dialética e da maiêutica, ${ }^{4}$ elabora-se o perguntar no intuito de refutar a tese contrária pela contradição, preparando o novo argumento. Para Calado (2001), há uma influência do pensamento socrático na filosofia freiriana, principalmente, em relação ao autoconhecimento e aprofundamento introspectivo da condição humana.

Procurando uma aproximação à proposta socrática, infere-se como ponto em comum a sistematização da dúvida, quando, por análises e sínteses, é possível exercer provocações sobre as questões em discussão, no intuito de fazer surgirem novos saberes. Os relatos em Freire (2002) são extraídos, primeiramente, de uma visita do autor a um assentamento da reforma agrária, distante de Santiago, no Chile, e, posteriormente, com trabalhadores no corte da cana no Brasil, especificamente no Estado de Pernambuco. Os círculos de cultura ${ }^{5}$ constituídos tornaram-se os momentos nos quais Freire se propôs a acompanhar o processo de leitura da palavra e de releitura de mundo.

Ao iniciar o diálogo com o grupo de campesinos, no Chile, mesmo que, de modo geral, Freire evitasse fazê-lo por causa do idioma, ${ }^{6}$ solicitou

\footnotetext{
4 A maiêutica propõe ao sujeito descobrir gradativamente o conhecimento sobre o objeto de discussão. Para Japiassu e Marcondes (2001), a maiêutica consiste em um procedimento no qual Sócrates, "[...] partindo das opiniões que seu interlocutor tem sobre algo, procura fazê-lo cair em contradição ao defender seus pontos de vista, vindo assim a reconhecer sua ignorância acerca daquilo que julgava saber." (JAPIASSU; MARCONDES, 2001, p. 123). Desse modo, a partir do reconhecimento da ignorância, passa-se a descobrir, pela razão, a verdade.

5 - círculo de cultura traduz para a educação uma forma organizacional para trabalhos em grupos em que os educadores são vistos como coordenadores ou monitores do processo de ensino e aprendizagem, tal que a proposta preconiza uma igualdade de participações. Freire (1980) enfatiza a importância dos círculos como momentos nos quais é possível discutir, organizar e planificar ações no coletivo. Os círculos de cultura remetem às experiências de Paulo Freire no Movimento de Cultura Popular em Recife, PE, no Projeto de Educação de Adultos, entre os anos 1950 e 1960. No círculo de cultura, em "[...] lugar do professor, com tradições fortemente "doadoras", o Coordenador de Debates. Em lugar de aula discursiva, o diálogo. Em lugar de aluno, com tradições passivas, o participante de grupo. Em lugar dos "pontos" e de programas alienados, programação compacta, "reduzida"e "codificada" em unidades de aprendizado." (FREIRE, 1969, p. 103, grifo do autor).

6 Nas palavras de Freire: "Senti um forte desejo de tentar um diálogo com o grupo de camponeses. De modo geral, evitava fazê-lo por causa da língua. Temia que meu "castanhês" prejudicasse o bom andamento dos trabalhos." (FREIRE, 2002, p. 46, grifo do autor).
} 
licença ao educador que coordenava a discussão do grupo, perguntando a esse se aceitava uma conversa. "Depois da aceitação, começamos um diálogo vivo, com perguntas e respostas de mim e deles a que, porém, se seguiu, rápido, um silêncio desconcertante." (FREIRE, 2002, p. 46).

A intencionalidade freiriana constitui-se em resgatar a história dos sujeitos envolvidos na discussão. As colocações do autor criam espaços para uma atividade preliminar no que trata a ação de conhecer os sujeitos, proporcionando uma atmosfera de proximidade entre esses. Nessa relação, o sujeito se constitui com o outro, com identidade, e não como um desconhecido.

Na sequência, surge o questionamento de um camponês: "'Desculpe, senhor', disse um deles, 'que estivéssemos falando. $\bigcirc$ senhor é que podia falar porque o senhor é o que sabe. Nós, não'." (FREIRE, 2002, p. 46). Freire percebe a exigência de seu interlocutor, mas nega a preleção com o intuito de reforçar uma ideologia já explicitada. Pelo contrário, propõe a compreensão a partir da aceitação de algo argumentado no discurso do camponês, problematizando-o e trazendo-o ao diálogo.

\footnotetext{
"Muito bem", disse em resposta à intervenção do camponês. "Aceito que eu sei e vocês não sabem. De qualquer forma, gostaria de lhes propor um jogo que, para funcionar bem, exige de nós absoluta lealdade. Vou dividir o quadro-negro em dois pedaços, em que irei registrando, do meu lado e do lado de vocês, os gols que faremos eu, em vocês; vocês, em mim. $\bigcirc$ jogo consiste em cada um perguntar algo ao outro. Se o perguntado não sabe responder, é gol do perguntador. Começarei o jogo fazendo uma primeira pergunta a vocês". (FREIRE, 2002, p. 48, grifo do autor).
}

Para Freire (2002), ensinar e aprender representam momentos de um processo maior, ou seja, o de conhecer, o qual implica reconhecer, pois “[...] o educando se torna realmente educando quando e na medida em que conhece, ou vai conhecendo os conteúdos, os objetos cognoscíveis, e não na medida em que o educador vai depositando nele a descrição dos objetos, ou dos conteúdos." (FREIRE, 2002, p. 47). Na sequência, Freire assume o jogo com o grupo, iniciando os questionamentos: "- Que significa a maiêutica socrática? 
Gargalhada geral e eu registrei o meu primeiro gol. - Agora cabe a vocês fazer a pergunta a mim - disse. Houve uns cochichos e um deles lançou a questão: - Que é curva de nível? Não soube responder. Registrei um a um." (FREIRE, 2002, p. 48). Dessa forma, o autor segue o diálogo:

- Qual a importância de Hegel no pensamento de Marx? Dois a um. - Para que serve a calagem do solo? Dois a dois. - Que é um verbo intransitivo? Três a dois. - Que relação há entre curva de nível e erosão? Três a três. - Que significa epistemologia? Quatro a três. - $\bigcirc$ que é adubação verde? Quatro a quatro. Assim, sucessivamente, até chegarmos a dez a dez. (FREIRE, 2002, p. 48).

Freire sugere aos camponeses a reflexão sobre o acontecido: inicialmente a discussão, segue-se o silêncio e, finalmente, o jogo. A discussão pela novidade no círculo de cultura, como momento de aproximação dos sujeitos; o silêncio, por apontar o autor como um sábio a fazer uma preleção e, por fim, o jogo, pela ironia em trabalhar o conhecimento. $\bigcirc$ relato na obra freiriana aponta para outro diálogo ocorrido na Zona da Mata, em Pernambuco, anterior ao período de exílio de Paulo Freire, diálogo semelhante ao dos camponeses chilenos, o qual inicia com o seguinte questionamento: "- Eu sei. Vocês não sabem. Mas por que eu sei e vocês não sabem?" (FREIRE, 2002, p. 49).

Freire propõe uma aprendizagem a partir do diálogo e, contrário às preleções e conferências, constitui seu modo de educar. Assim, o autor exercita, vagarosamente, a reflexão com o objetivo de construir um saber. Retomando o diálogo, Freire claramente intencionaliza a sua intervenção. Rapidamente, surge a resposta: "- $\bigcirc$ senhor sabe porque é doutor. Nós, não." (FREIRE, 2002, p. 49). Freire segue o diálogo:

- Exato, eu sou doutor. Vocês não. Mas, por que eu sou doutor e vocês não? - Porque foi à escola, tem leitura, tem estudo e nós, não. - E por que fui à escola? - Porque seu pai pôde mandar o senhor à escola. $O$ nosso, não. - E por que os pais de vocês não puderam mandar vocês à escola? - Porque eram camponeses como nós. - E o que é ser camponês? - É não ter educação, posses, trabalhar de sol a sol sem direitos, sem esperança de um dia melhor. - E 
por que ao camponês falta tudo isso? - Porque Deus quer. (FREIRE, 2002, p. 49).

Para Freire, os camponeses estavam tentando superar a relação proposta na obra Pedagogia do oprimido, no momento em que se constitui a aderência do oprimido ao opressor, fazendo, em um segundo instante, com que se tome distância do opressor para permitir localizá-lo fora de si próprio.

- E quem é Deus? - É o Pai de nós todos. - E quem é pai aqui nesta reunião? Quase todos de mão para cima, disseram que o eram. Olhando o grupo todo em silêncio, me fixei num deles e lhe perguntei: - Quantos filhos você tem? - Três. - Você seria capaz de sacrificar dois deles, submetendo-os a sofrimentos para que o terceiro estudasse, com vida boa, no Recife? Você seria capaz de amar assim? - Não! - Se você - disse eu -, homem de carne e osso, não é capaz de fazer uma injustiça desta, como é possível entender que Deus o faça? Será mesmo que Deus é o fazedor dessas coisas? Um silêncio diferente, completamente diferente do anterior, um silêncio no qual algo começava a ser partejado. Em seguida: - Não. Não é Deus o fazedor disso tudo. É o patrão! (FREIRE, 2002, p. 49-50).

Nos movimentos realizados, é possível identificar o opressor. A partir dessa ideia, o oprimido compreende o papel do patrão, inserido no sistema socioeconômico e político, problematizando as relações sociais de produção e os interesses de classe. Assumindo como foco as relações educativas, Freire afirma que viver enquanto educador significa reconhecer nos outros o direito de dizer a sua palavra, direito de alguém falar ao que corresponde, de igual forma, o dever da escuta. $\bigcirc$ diálogo constitui-se um articulador do entendimento entre os sujeitos, proporcionando um exercício entre iguais e diferentes, no qual é permitido ouvir o outro, com alteridade. Proposta de um diálogo fundamentado na humildade, em detrimento da autonomia, pois não há diálogo se não existe humildade.

Na obra Pedagogia do Oprimido, quando Freire (2004) remete ao direito de dizer a palavra, o faz no sentido de que o ato de dizer a palavra verdadeira seja o de transformar o mundo, pressupostos esses imbricados 
ao conceito de práxis, ${ }^{7}$ como ação e reflexão, situadas por argumentos da educação libertadora. $\bigcirc$ autor argumenta que o ser humano, pela sua própria condição existencial, é aquele que deve pronunciar ${ }^{8}$ e modificar o mundo. É nessa compreensão que "[...] o mundo pronunciado, por sua vez, se volta problematizado aos sujeitos pronunciantes, a exigir deles novo pronunciar." (FREIRE, 2004, p. 78). $\bigcirc$ pronunciar e modificar o mundo constitui-se como direito de todos os seres humanos, não como privilégio de alguns, de tal maneira que ninguém deva dizer a palavra verdadeira sozinha ou dizer para os outros, mas pronunciá-la na relação de partilha com os outros.

Essa é a razão que remete à impossibilidade do diálogo entre os que desejam a pronúncia da palavra verdadeira e os que não a querem ou, de outra maneira, "[...] entre os que negam aos demais o direito de dizer a sua palavra e os que se acham negados deste direito." (FREIRE, 2004, p. 79). Ao pronunciarem o mundo pela palavra verdadeira, os seres humanos transformam e humanizam esse mesmo mundo, e o diálogo passa a constituir-se como caminho para que os sujeitos ganhem significação enquanto seres. É a partir desses pressupostos que o diálogo se torna fundamentação como ato colaborativo dos seres humanos, problematizando o mundo em prol da libertação destes.

A proposta freiriana adverte para as armadilhas de um falso diálogo como a polêmica em torno da verdade, principalmente quando se deseja a imposição de uma dada verdade, preestabelecida, ou quando se constitui o ato de depositar ideias como aquelas que serão consumidas pelos seres humanos.

\footnotetext{
7 A práxis, categoria de base marxiana, estabelece uma ação transformadora consciente e crítica da realidade, superando a dicotomia teoria e prática. Essa ação desencadeia a construção de um novo modelo conceitual em que o sujeito passa a atuar e interferir sobre o contexto no qual está inserido. "É na práxis que o ser humano tem de provar a verdade, isto é, a realidade e o poder, o caráter terreno de seu pensar." (MARX; ENGELS, 2010, p. 27). Conforme Sánchez Vázquez (2007): "A relação entre teoria e práxis é para Marx teórica e prática; prática, na medida em que a teoria, como guia da ação, molda a atividade do homem, particularmente a atividade revolucionária; teórica, na medida em que essa relação é consciente." (SÁNCHEZ VÁZQUEZ, 2007, p. 109). Compreende-se que a ação libertadora freiriana, tomando por base uma relação dialógica, é histórica, reafirmando a formulação de pensamentos idealizados e vinculando o conhecimento a um objetivo concreto.

8 Na obra Pedagogia do oprimido, Freire (2004) elabora a diferença entre o dizer e o pronunciar. No caso, o dizer a palavra sozinho ou aos outros, como ato prescritivo, é como roubar a palavra aos demais. $\bigcirc$ autor enfatiza que o diálogo é o encontro dos seres humanos "[...] mediatizados pelo mundo, para pronunciá-lo, não se esgotando, portanto, na relação eu-tu." (FREIRE, 2004, p. 78).
} 


\section{A PRÁXIS SOCIAL E OS MOUIMENTOS DE AÇÃO-REFLEXÃO}

Na proposta freiriana, a práxis não é ação em si, sem intencionalidade nem finalidade, mas, pelo contrário, é ação-reflexão. Dessa maneira, os seres humanos constituem-se historicamente como seres da práxis e nela têm-se capacitado para transformar o mundo, a fim de lhe dar sentido. "Somente como seres da práxis (homens-ação), aceitando nossas situações-limites como desafios, podemos através de nossa ação, transformar o mundo." (FREIRE, 1979, p. 67).

A problematização, presente na obra Diálogos com Paulo Freire ${ }^{9}$ assume a necessidade do engajamento dos seres humanos ao contexto vivido, ao que conduz, segundo o próprio autor, ao encaminhamento radical à transformação sociocultural, dado um tempo histórico. Essa transformação sociocultural é ato, pois, para Freire, os seres humanos fazem sua história a partir de uma situação concreta, um tempo-espaço de possibilidades. Nessas condições, não há espaço para um subjetivismo, o qual apregoa apenas a transformação da consciência, mas um subjetivismo, que age sobre a realidade. Nessa mesma linha de raciocínio, não há espaço para o objetivismo mecanicista, $^{10}$ o qual dicotomiza a relação sujeito-objeto, mas é preciso compreender essa relação na unidade dialética a qual une a teoria e a prática, numa construção de relações contraditórias e dinâmicas.

$\bigcirc$ autor nega o predeterminismo e argumenta que o futuro vai acontecendo, que o "[...] futuro existe na medida em que eu ou nós mudamos o presente. E é mudando o presente que a gente fabrica o futuro: por isso, então a história é possibilidade e não determinação." (FREIRE, 1991, p. 90). Essa

\footnotetext{
9 A obra Diálogos com Paulo Freire, de autoria de Carlos Alberto Torres, disponibiliza várias entrevistas com Freire, entre elas a entrevista aqui utilizada, publicada orginalmente em 1973 pelo Instituto de Ação Cultural, denominada Concientização e libertação: conversa com Paulo Freire, a qual possui como título original: Conscientization e liberation, introduction a la discussion avec Paulo Freire.

10 Freire (2013) remete ao objetivismo mecanicista como uma compreensão de mundo a qual está fundamentada em uma explicação objetiva e unilateral da realidade, um reducionismo dos seres humanos a objetos, rompendo, dessa maneira, com a dialetização do processo.
} 
concepção estabelece como convocatória a luta ${ }^{11}$ na qual os seres humanos, em coletivos, vivem as mais diversas maneiras de opressão. Não é a história que utiliza os seres humanos para atingir algo, mas é a ação desses seres, na busca pelos objetivos da categoria, que constituirá essa história.

Esse é o momento em que os seres humanos, tomando as "situaçõeslimites"12 como desafios, como seres da práxis, admirando o "inédito viável"13 como maneira de concretização, poderão materializar, na "ação editanda", as ações de transformação do mundo. A práxis pode ser refletida como o conjunto das relações entre o modo de compreender criticamente a realidade e a consequente prática que decorre dessa compreensão, com ações transformadoras. A proposta freiriana, a partir desses pressupostos, enuncia que o ser humano, em dado momento de transição da passagem da consciência ingênua à consciência crítica, passa a compreender o seu papel no mundo, por meio de uma teoria que o torna capaz de interpretar esse momento histórico. Tal situação leva esse ser a um segundo momento, no qual o sujeito passa a dizer a sua palavra e, consequentemente, a agir para transformar a realidade em que está inserido.

Aqui se constrói uma relação entre o pensar-dizer a sua palavra e o agir, dado que a consciência se plenifica na palavra e na ação. Na obra Cartas a Guiné-Bissau: registros de uma experiência em processo, Freire (1978) reflete sobre a experiência em Bissau, com a alfabetização de trabalhadores

\footnotetext{
11 O termo luta empregado por Freire (2004) na obra Pedagogia do oprimido remete à luta dos oprimidos, como movimento de humanização, inserido em um contexto histórico, no qual esses seres humanos buscam resgatar a sua humanidade roubada. "E esta luta somente tem sentido quando os oprimidos, ao buscarem recuperar sua humanidade, que é uma forma de criá-la, não se sentem idealistamente opressores, nem se tornam de fato, opressores dos opressores, mas restauradores da humanidade em ambos." (FREIRE, 2004, p. 30).

12 Para Freire (2004), o universo mínimo temático é composto por temas os quais, em geral, se contradizem, e por vezes mantêm estruturas já existentes, onde se estabelece uma relação de correspondência entre os temas geradores e o contexto histórico do qual os seres humanos fazem parte, possibilitando perceber a inserção dos envolvidos na temática. $\bigcirc$ autor argumenta que os temas geradores, não raro, encontram-se encobertos pelo que compreende como "situações-limites", as quais se apresentam como determinantes históricas, permitindo aos seres uma adaptação à realidade em que se encontram. Quandos esses seres humanos não estão envolvidos e envolvendo as "situações-limites" as respostas desses mesmos não serão autênticas.

13 No momento em que os seres humanos se percebem na fronteira entre o ser e o "ser mais" está implícito o "inédito viável", como aqueles projetos e atos das possibilidades humanas, com intensidade afetiva, cognitiva, política e ética.
} 
adultos, ${ }^{14}$ relações educativas essas consideradas como ato político. processo caracterizava-se como aprendizado crítico de leitura e escrita, e não como memorização alienante de palavras e/ou frases. Para o mesmo autor, o importante não é o aprendizado da leitura e da escrita como exercício dessas atividades dissociado da compreensão crítica do contexto social, mas uma leitura e escrita que possibilitem uma percepção e aprofundamento da realidade na qual o fundamental é fazer a história, permitindo ao sujeito exercer a reflexão sobre a razão de ser das próprias situações enfrentadas.

Freire (1978) afirma, considerando o espaço de inserção de um educador progressista, que não há neutralidade na educação, pois o ser humano que se assume neutro é aquele que está a serviço do modelo de memorização alienante, o qual favorecerá, por fim, a classe dominante. Inserido no contexto de alfabetização de adultos e considerando, ainda, para além desse espaço, Freire assume que o tipo de processo educativo fundamentado na neutralidade "[...] interessa às classes dominantes quando, por diferentes razões, necessitam estimular, entre as classes dominadas, a sua 'introdução ao mundo das letras'." (FREIRE, 1978, p. 27, grifo do autor). A partir desses pressupostos, o autor reflete que, quanto mais próxima da neutralidade as classes dominadas fizerem a sua entrada neste mundo, melhor será para as classes dominantes. Nesses movimentos, irrompe um pensamento desligado da objetividade, o qual não discute os mecanismos de introjeção da ideologia, pois se veicula a um conhecimento que será adquirido como forma de erradicação, ${ }^{15}$ como recepção passiva, na qual os seres humanos são apenas objetos de um processo.

\footnotetext{
14 Na obra Cartas a Guiné-Bissau: registros de uma experiência em processo, Freire (1978), entre os anos 1975 e 1976, insere-se no contexto de alfabetização de adultos em Bissau, na África, onde duas iniciativas haviam sido iniciadas: uma ligada às Forças Armadas do Povo (FARP) e a outra, ao Comissariado de Educação.

15 Quando Freire (1978) utiliza o termo erradicação, o faz no sentido de que o analfabetismo, nesse contexto de opressão, é considerado como uma enfermidade pela classe dominante. Utiliza outros termos, como erva daninha ou, ainda, chaga. $O$ processo de alfabetização que visa a combater esse mal possui como pressupostos introduzir os seres humanos nos processos de leitura e escrita, mantendo a neutralidade da classe oprimida, pois os mecanismos ideológicos da classe dominante não são postos em discussão. Daí que os seres humanos continuem como "[...] objetos no contexto geral da sociedade de classes, enquanto oprimidos e proibidos de ser, os analfabetos continuam objetos no processo de leitura e escrita." (FREIRE, 1978, p. 27).
} 
Na perspectiva progressista crítica, os educandos são convidados a pensar como seres que sabem o que conhecem. $\bigcirc$ aprendizado da leitura e da escrita torna-se um ato criador, o qual envolve a compreensão crítica da realidade. $\bigcirc$ movimento do pensar, quando o educando passa a conhecer o conhecimento anterior, analisando sua prática no contexto, abrelhe a possibilidade a um novo conhecimento, no qual esse sujeito, indo além dos limites do anterior, desvela a razão dos fatos, o que desmistificará suas falsas interpretações. A partir desses pressupostos, Freire afirma que não há separação entre pensamento-linguagem e realidade objetiva, refletindo que são necessárias ações as quais ganhem centralidade, como a sistematização do conhecimento, a qual os trabalhadores alcançam em decorrência de sua atividade prática, que não se explica por si mesma, mas por sua finalidade; a reorganização do modo de produção; e a valoração, e não a ideologia, da sabedoria popular, a qual "[...] envolve a atividade criadora do povo e revela os níveis de seu conhecimento em torno da realidade." (FREIRE, 1978, p. 29).

A questão que se faz pertinente não é transmitir ao ser humano um conhecimento já elaborado, desconhecendo o que este já sabe, mas conhecer o que ele sabe, de forma desorganizada, e devolver a esse sujeito o conhecimento de forma organizada. Essa tarefa significa desafiar ${ }^{16}$ esse sujeito, por meio da reflexão crítica sobre sua própria prática, sobre as finalidades que a motivam, "[...] a organizar os seus achados, superando, assim, a mera opinião sobre os fatos por uma, cada vez mais rigorosa, apreensão e explicação dos mesmos." (FREIRE, 1978, p. 29).

Um trabalho fundado na prática de pensar a própria prática, como prática que se renova, por meio de um trabalho sistematizado do conhecimento e de uma postura crítica, constitui-se, permanentemente, um aprofundamento

\footnotetext{
16 Quando Freire (1978) utiliza o termo desafiar, remete a Amilcar Cabral, revolucionário à frente das lideranças do, então, Partido Africano para a Independência da Guiné e Cabo Verde (PAIGC). Freire nunca se encontrou com Amilcar Cabral, mas estudou seu envolvimento e obra, principalmente com relação à inserção de Cabral na alfabetização de adultos e no projeto de reconstrução nacional. Freire inicia seus estudos sobre o autor em Genébra, dando continuidade em sua viagem à África. Em relação ao termo, Freire compreende os trabalhos desse autor como um: "[...] desafio a que Amilcar Cabral dava séria atenção quando, analisando a luta de libertação como 'um fato cultural e um fator de cultura', sublinhava a necessidade de que essa cultura se fosse tornando cada vez mais científica e não cientificista - sobrepassando, então o que ele costumava chamar de 'fraqueza da cultura'." (FREIRE, 1978, p. 29, grifo do autor).
} 
na realidade em questão. Dessa maneira, a alfabetização, para Freire (1978), tem como objetivo ultrapassar o caráter imediatamente utilitário da atividade prática, no intuito de torná-la, permanentemente, um objeto de estudo que resulte em uma compreensão desta, tendo nela não apenas a sua razão de ser, mas a fonte de conhecimentos a ela referidos.

\section{OS DESAFIOS QUE ENFRENTA O MOMENTO CONTEMPORÂNEO}

Aproximando a discussão elaborada até aqui à concepção da escola contemporânea, compreende-se que tanto os educadores quanto os educandos estão tomados por fragmentos impostos pelos modelos de produção e consumo vigentes, fragmentos esses os quais geram minorias culturais diversificadas. A reflexão aqui argumentada remete ao seguinte questionamento: ante a diferença com a qual educadores e educandos vão para a sala de aula, como é possível atuar a favor da transformação do complexo momento cultural exposto, quando pares conceituais, como universal e fragmento, identidade e diferença, são, de forma maniqueísta, postos em irreconciliável oposição?

Considerando o questionamento, torna-se fundamental que os sujeitos envolvidos na relação educativa consigam identificar e discernir as semelhanças e diferenças presentes no contexto vivido. Nessas condições, o diálogo freiriano, a partir de sua dimensão ontológica, permite que a partilha entre educador e educandos ganhe centralidade, redefinindo o quadro do poder entre os sujeitos envolvidos.

Freire, com o foco na educação popular pelo diálogo, toma como ponto de partida o quadro antropológico-cultural, o qual está intimamente ligado à vida daqueles que participam da relação educativa. Dessa maneira, o universo temático, o mundo da cultura dos sujeitos envolvidos, permite a construção do universo vocabular. A partir dessas ideias, na relação dialógica, a compreensão do mundo para a sua transformação ganha centralidade, mas, ao mesmo tempo, compreende-se o alerta da proposta freiriana quanto à existência de um quadro perverso do poder, instituído na luta de classes, constituindo-se 
necessário que se fundamentem as relações educativas partindo, sempre, do mundo da vida das pessoas. Tal pressuposto não requer que se abra mão do conteúdo programático, mas sustenta a ideia de que o ensinar e o aprender fazem parte do mesmo processo de conhecer e que o diferencial é o ato de ensinar como conhecer.

Nessa linha de discussão, Freire argumenta que é tarefa do educador testemunhar "[...] aos estudantes como você estuda, como você se aproxima do objeto de seu conhecimento, o que significa para você a busca do conhecimento." (FREIRE, 1991, p. 115). A afirmação demonstra a contrariedade de Freire ao discurso conceitual do objeto em questão, em detrimento do exercício do como conhecer. É partindo do mundo da vida, fundamentado na relação dialógica, que o autor desafiará os sujeitos a uma compreensão da realidade constituída, na qual o aprendizado, pela busca desse conhecimento, ganha centralidade. Já o contrário, simplesmente, o ato de transmitir esse mesmo conhecimento é impeditivo ao desenvolvimento do pensamento freireano.

Retomando a discussão a respeito da escola contemporânea, não raro, nas relações educativas há a percepção de que os materiais utilizados são devidamente acabados e finitos e, por vezes, não despertam interesse aos educandos. A partir dessa constatação, é possível refletir que o monólogo associado às cartilhas ${ }^{17}$ conteudistas ainda se faça presente na maior parte das atividades educativas, provocando distorções na formação dos educandos. $\bigcirc$ trabalho de Freire mostra que o desafio é a reconstrução do então construído,

17 Ghiggi (2010) reafirma que Freire não acatava a cartilha pronta, aceitando o desafio de construí-la, pressuposto esse o qual define o nascimento e importância da relação dialógica no pensamento freiriano. Paulo Freire, entre os anos 1950 e 1960, atuando no Movimento de Cultura Popular em Recife, PE, elabora um amplo estudo das cartilhas em circulação. "Nelas encontra sentenças culturais, antropológicas, epistemológicas e éticas não condizentes com a visão de mundo e de humano que o seu tempo indicava necessárias para dar conta das imperativas mudanças." (GHIGGI, 2010, p. 113). Na obra Educação como prática da liberdade. Freire (1969) demonstra sua descrença nas cartilhas quando afirma que "[...] essas pretendem a montagem da sinalização gráfica como uma doação e reduzem o analfabeto à condição de objeto que à de sujeito de sua alfabetização." (FREIRE, 1969, p. 11 l, grifo do autor). Para o mesmo autor, o fundamental na alfabetização, em uma língua silábica, é que o ser humano possa apreender criticamente o seu mecanismo de formação vocabular, para que ele mesmo faça o jogo criador das combinações. 
por meio da elaboração de novas práticas culturais que demonstrem a dimensão do inacabamento ${ }^{18}$ do ser humano como caminho a ser seguido.

Aproximando o diálogo freiriano com os camponeses chilenos e trabalhadores da Zona da Mata à discussão, percebe-se que a ideia de Freire, quando nega ${ }^{19}$ uma preleção, é de propor uma ação dialógica com os interlocutores, tornando-se, ao mesmo tempo, conhecedor da história desses sujeitos. A intencionalidade freiriana em resgatar a história dos envolvidos na discussão é assumida como elemento fundante para a reflexão. $\bigcirc$ conhecer a visão de mundo dos sujeitos promove a constituição do outro, visto que o diferente, aquele que é estranho, passa a constituir-se como o outro.

Ao conhecer a visão de mundo dos educandos, é possível que o educador se assuma imerso nessa realidade, possibilitando que todos possam emergir criticamente conscientes para com o contexto sócio-histórico e cultural. Dessa maneira, o exercício do diálogo assume o sentido de despertar nos seres humanos processos de modificações pessoais que lhes permitam experienciar atividades de sua existência, a partir de um coletivo inserido na realidade histórica.

A relação dialógica freiriana parte da pronúncia do mundo pela palavra verdadeira, com a qual os seres humanos transformam e humanizam esse mundo. Nesse movimento, o diálogo passa a constituir-se como caminho para que os sujeitos ganhem significação enquanto seres. Desse modo, a relação dialógica realiza-se na dimensão política da educação, quando, partindo de uma situação concreta, faz repensar a prática, instituindo processos de transformação. Essa relação dialógica como exercício da comunicabilidade e da reciprocidade, fundamentada na essência humana que se constitui a partir da existência do ser, está vinculada a um dado contexto histórico. Essa essência que se recria, articulando-se ao processo de conscientização, possui

\footnotetext{
18 A consciência do inacabamento em Freire é uma dimensão "[...] indispensável ao processo de construção da autonomia e da produção da educação a serviço da transformação, pois tal dimensão permite ao humano inserir-se num processo de fazer e refazer a história." (GHIGGI, 2010, p. 117).

19 A ideia de negação em Freire supera a dicotomia de quem rejeita, impossibilitando a verdade que oprime. Ao negar, Freire está assumindo outra opção política em educação.
} 
por objetivo constituir um sujeito em favor das transformações sociais, autor de sua própria história.

Retomando a reflexão, compreende-se uma contradição, já que a prática escolar acrítica pensada e exercitada é, na maioria das vezes, uma prática pedagógica associada aos conteúdos programáticos a serem estudados. As atividades estabelecidas estão alinhadas aos processos cognitivos que venham a se organizar como facilitadores do aprendizado dos educandos. A partir dessa afirmativa, justifica-se que na escola contemporânea é como se fosse possível separar o educando de sua existência, ao se propor uma redução ao seu contexto escolar.

Por outro lado, a proposta freiriana remete aos processos de transformação sociais. A prática educativa crítica, no contexto freiriano, está associada ao trabalhar e pensar a existência do ser humano em seu próprio contexto histórico. Mesmo em uma realidade de redução ao contexto escolar, a qual apresenta com discrição o mundo da vida do educando, para Freire essa relação educativa, pela possibilidade da leitura e da escrita sobre os conteúdos, inserida em um contexto por um aprender por si mesmo, será facilitadora para que o educando, aos poucos, desenvolva a oportunidade de correlacionar seu contexto histórico e suas relações sociais.

Admite-se que o contexto freiriano está vinculado à educação popular, e a problematização em questão, à educação formal, espaço esse último no qual é viável constituir a ideia de que, pela reflexão associada à leitura e à escrita, poder-se-ia passar da ingenuidade a uma visão crítica, de forma gradativa. Não se tem como intuito dicotomizar os dois contextos, tornandoos irreconciliáveis, mas refletir que, na educação popular, o aprendizado do educador constitui-se quando esse sujeito, na apreensão da realidade dos educandos, ressignifica seus saberes científicos, à medida que apreende os saberes provenientes dos sujeitos envolvidos na relação educativa. Da mesma maneira, o educando aprende quando, pelo conhecimento científico trabalhado, ressignifica seus saberes do cotidiano e consegue gerar ações que venham a provocar transformações no meio em que está inserido. 
Por outro lado, no contexto escolar, mesmo com todo o esforço pedagógico dos educadores, os saberes dos educandos, de seu tempo histórico, ficam subsumidos aos conhecimentos científicos trabalhados. A partir dessa constatação, o aprendizado dos educadores também se torna prejudicado, visto que os saberes estão, temporariamente, dicotomizados. Argumenta-se, da mesma maneira, que esse contexto escolar está submisso aos modos de produção capitalista, e, nesse cenário, o desenvolvimento educacional tornase uma exigência do próprio modelo, que carece de formação adequada para diferentes postos de trabalho. Nessas circunstâncias, as falhas em promover uma crítica social e a submissão ao modo capitalista deveriam configurar as "situações-limites" para os educadores. São as "situações-limites" que fazem os sujeitos promoverem estratégias pedagógicas na direção de que os conhecimentos científicos trabalhados venham a empoderar os educandos, para que, a partir da ressignificação dos saberes, esses sujeitos possam constituir ações em favor da transformação social.

As "situações-limites" estão sempre relacionadas à prática social dos educandos. Para Freire, o ponto de partida é, justamente, essa prática associada ao saber do educador. A prática, a ação, representa um dos eixos em torno do qual o processo educativo constituir-se-á, e, pelas elaborações teóricas, a reflexão, é possível apreender e analisar os saberes vivenciados pelos seres humanos inseridos no processo educativo.

Nos movimentos de ação-reflexão, a análise crítica é elaborada partindo da prática social a qual está inserida nas situações concretas pela codificação. $\bigcirc$ diálogo, nessa perspectiva, constitui o repensar a prática anterior, pelo processo de descodificação, o qual instaura uma nova prática, mantendo a unidade entre o contexto teórico e o concreto. De forma contrária, os educadores, não raro, propõem as atividades considerando como ponto de partida não a realidade dos educandos, mas a realidade idealizada por esses sujeitos. Dessa maneira, os conteúdos discutidos a respeito dos conhecimentos científicos teóricos são, inicialmente, trabalhados e, em um segundo momento, quando possível, são elaboradas as aproximações a um contexto vivido.

Por fim, compreende-se que o fazer e o refazer o mundo, como tarefa de transformação social, promovem uma renovação cultural, a qual não 
é dada em um momento determinado, mas deve estar presente nas situações existenciais dos seres humanos. Esse trabalho humanizante equivale ao trabalho da desmitificação no qual, por meio da conscientização, o ser humano constitui um olhar crítico da realidade e a desvela para conhecê-la, percebendo os mitos que ajudam a manter a estrutura opressora.

\section{CONSIDERAÇÕES FINAIS}

A proposta freiriana parte do mundo da vida, e, pela relação dialógica, os seres humanos são desafiados a uma compreensão da realidade constituída, na qual o aprendizado, pela construção do conhecimento, ganha centralidade. A compreensão da realidade exige do sujeito o exercício de tomar distância do objeto para que, contraditoriamente, aproxime-se dele para conhecê-lo criticamente.

De maneira resumida, refletiu-se a respeito de três ideias-força:

a) a relação dialógica entre os sujeitos exige uma escuta da prática - o diálogo deve priorizar a vocação ontológica do ser humano, vocação de ser sujeito, promovendo a compreensão do contexto e dos saberes dos envolvidos na relação. $\bigcirc$ pronunciar e modificar o mundo constitui-se um direito de todos os seres humanos, não como privilégio de alguns, de tal maneira que ninguém deva dizer a palavra verdadeira sozinha ou dizer para os outros, mas pronunciá-la na relação de partilha com os outros;

b) ter o contexto vivido, ou a leitura da realidade, como ponto de partida - ao pronunciar o mundo, pela palavra verdadeira, os seres humanos transformam e humanizam esse mesmo mundo, e o diálogo passa a constituir-se um caminho para que os sujeitos ganhem significação enquanto seres. $\bigcirc$ diálogo fundamentado na leitura da realidade torna-se um ato colaborativo dos seres 
humanos, os quais problematizam o mundo em prol de sua humanização e libertação;

c) a relação educativa demanda a reflexão crítica - a reflexão crítica teórica remete àquele educador que está situado para além de um estudo descontextualizado dos conteúdos programáticos a serem trabalhados na relação educativa. $\bigcirc$ foco está em como esse educador potencializa esses saberes, relacionando-os ao dinanismo da época em que vive e ao contexto socio-histórico no qual está inserido.

Nesse sentido, tanto a educação popular quanto a educação formal assumem seu papel no momento em que marcham na direção da constituição de uma nova realidade e, ao mesmo tempo, denunciam as estruturas desumanizantes. Para que isso aconteça, o processo educativo deve partir da realidade dos educandos, e, pelo movimento de ação-reflexão, é possível manter a constante dialetização entre objetividade e subjetividade.

Por fim, compreende-se que assumir na relação dialógica as situações existenciais e vivenciais da cotidianidade, as quais permitam aos seres humanos o debate de temas desafiadores que envolvam e sejam envolvidos pelas "situações-limites", recuperando a vocação ontológica do ser mais, é condição fundamental para o respeito e a partilha entre educadores e educandos, os quais se tornam ferramentas necessárias à dignificação dos sujeitos envolvidos nas relações educativas.

\section{REFERÊNCIAS}

CALADO, A. J. F. Paulo Freire: sua visão de mundo, de homem e de sociedade. Caruaru: FAFICA, 2001.

FREIRE, P. Ā educação na cidade. São Paulo: Cortez, 1991.

FREIRE, P. Cartas à Guiné-Bissau: registros de uma experiência em processo. 2. ed. Rio de Janeiro: Paz e Terra, 1978. 
FREIRE, P. Conscientização e libertação: conversa com Paulo Freire. In: TORRES, C. A. T. (Org.). Diálogo com Paulo Freire. Loyola: São Paulo, 1979. p. 63-77.

FREIRE, P. Educação como prática da liberdade. 2. ed. Rio de Janeiro: Paz e Terra, 1969.

FREIRE, P. Extensão ou comunicação? 16. ed. Rio de Janeiro: Paz e Terra, 2013.

FREIRE, P. Pedagogia da esperança: um reencontro com a pedagogia do oprimido. 9. ed. Rio de Janeiro: Paz e Terra, 2002.

FREIRE, P. Pedagogia da indignação. São Paulo: Paz e Terra, 2014.

FREIRE, P. Pedagogia do oprimido. 38. ed. São Paulo: Paz e Terra, 2004.

FREIRE, P. Quatro cartas aos animadores de círculos de cultura de São Tomé e Príncipe. In: BEZERRA COSTA, M. A.; BRANDÃO, C. R. (Org.). A questão política da educação popular. São Paulo: Brasiliense, 1980. p. 136-195.

GHIGGI, G. Paulo Freire e a revivificação da educação popular. Educação, Porto Alegre, v. 33, n. 2, p. 111 -1 18, maio/ago. 2010.

JAPIASSU, H.; MARCONDES, D. Dicionário básico de filosofia. 3. ed. Rio de Janeiro: Jorge Zahar, 2001.

MARX, K.; ENGELS, F. A ideologia alemã. Rio de Janeiro: Civilização Brasileira, 2010 .

SÁNCHEZ VÁZQUEZ, A. Filosofia da práxis. São Paulo: Expressão Popular, 2007.

Recebido em 28 de janeiro de 2018

Aceito em 23 de agosto de 2018

Endereços para correspondência: Av. Itália, km 8, Campus Carreiros, 96021 900, Vila Maria, Rio Grande, Brasil; dmtalcf@furg.br 
